\title{
Changes in atmospheric variability in a glacial climate and the impacts on proxy data: a model intercomparison
}

\author{
F. S. R. Pausata ${ }^{1,2}$, C. Li ${ }^{1,3}$, J. J. Wettstein ${ }^{1}$, K. H. Nisancioglu ${ }^{1}$, and D. S. Battisti ${ }^{4,2}$ \\ ${ }^{1}$ Bjerknes Centre for Climate Research, Allegaten 55, 5007 Bergen, Norway \\ ${ }^{2}$ Geophysical Institute, University of Bergen, Allegaten 70, 5007 Bergen, Norway \\ ${ }^{3}$ Department of Earth Science, University of Bergen, Allegaten 41, 5007 Bergen, Norway \\ ${ }^{4}$ Department of Atmospheric Sciences, University of Washington, Seattle, WA 98195, USA
}

Received: 11 February 2009 - Published in Clim. Past Discuss.: 12 March 2009

Revised: 1 August 2009 - Accepted: 21 August 2009 - Published: 11 September 2009

\begin{abstract}
Using four different climate models, we investigate sea level pressure variability in the extratropical North Atlantic in the preindustrial climate $(1750 \mathrm{AD})$ and at the Last Glacial Maximum (LGM, 21 kyrs before present) in order to understand how changes in atmospheric circulation can affect signals recorded in climate proxies.

In general, the models exhibit a significant reduction in interannual variance of sea level pressure at the LGM compared to pre-industrial simulations and this reduction is concentrated in winter. For the preindustrial climate, all models feature a similar leading mode of sea level pressure variability that resembles the leading mode of variability in the instrumental record: the North Atlantic Oscillation (NAO). In contrast, the leading mode of sea level pressure variability at the LGM is model dependent, but in each model different from that in the preindustrial climate. In each model, the leading (NAO-like) mode of variability explains a smaller fraction of the variance and also less absolute variance at the LGM than in the preindustrial climate.

The models show that the relationship between atmospheric variability and surface climate (temperature and precipitation) variability change in different climates. Results are model-specific, but indicate that proxy signals at the LGM may be misinterpreted if changes in the spatial pattern and seasonality of surface climate variability are not taken into account.
\end{abstract}

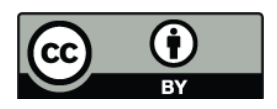

Correspondence to: F. S. R. Pausata (francesco.pausata@bjerknes.uib.no)

\section{Introduction}

Much of our knowledge about past climates comes from only a few locations, most notably Greenland and Antarctica, because it is difficult to obtain good quality, high resolution proxy records of long duration. It follows that data from single locations have been used to infer climate changes back in time at regional, hemispheric and even global spatial scales (e.g. Dansgaard et al., 1993; Jouzel et al., 1994; Shackleton, 2001). For example, the Greenland ice cores' oxygen isotope records have been used to reconstruct temperature as far back as the last interglacial (e.g. Dansgaard et al., 1993) using the modern climate temperature-isotope relationship. There is awareness of the potential pitfalls of assuming stationarity in the relationship between climate and signal captured by proxies, but in many cases there has been little investigation of the causes of non-stationarity and therefore few proposed solutions. The climate-proxy relationship cannot, however, be assumed to be stationary on climate change time scales. For instance, it has been suggested that changes in the position of the centers of action of the leading modes of climate variability (such as the North Atlantic Oscillation, NAO), shown in several studies (e.g. Christoph et al., 2000; Raible et al., 2006), have led to a change in the signal recorded by proxies (Hutterli et al., 2005).

Climate models can be a useful tool for assessing how internal atmospheric variability may be altered by external forcings, and how these changes may affect what the proxy data record. For example, model simulations suggest that persistent positive anomalies in the NAO index in the 1980s1990s are linked to increases in greenhouse gas concentrations (Shindell et al., 1999; Miller et al., 2006). Past climates offer a wider range of climate states to explore, in

Published by Copernicus Publications on behalf of the European Geosciences Union. 
addition to the possibility of comparing model simulations with proxy-based observations when and where these are available. Previous studies have shown that during the midHolocene (6000 yrs before present, $6 \mathrm{ka}$ ) warm interval, the atmosphere supports variability that has NAO-like characteristics similar to the pre-industrial (PI, 1750 AD) period (Gladstone et al., 2005). Last Glacial Maximum (LGM, $21 \mathrm{ka})$ simulations permit an exploration of the dominant patterns and seasonality of climate variability during an interval when the atmospheric circulation was substantially perturbed by the presence of large land-based ice sheets and by lower greenhouse gas concentrations. Simulations of the LGM cold climate exhibit substantial differences in both the mean state and variability of the extratropical circulation compared to PI simulations. These differences include: (1) a southward shift of the Pacific and Atlantic storm tracks (Laîné et al., 2008); (2) a shift (Justino and Peltier, 2005; Peltier and Solheim, 2002) and weakening (Otto-Bliesner et al., 2006) of the NAO's main centers of action; and (3) a decrease in interannual jet variability and storminess in the Atlantic sector $(\mathrm{Li}$ and Battisti, 2008). It is difficult, however, to evaluate how robust the changes in atmospheric variability are and how the relationship between changes in the atmospheric flow patterns and proxy signals might be expected to vary, because each of the aforementioned studies (with the exception of Laîné et al., 2008) was performed using a single model.

We present a model intercomparison of sea level pressure (SLP) variability in the extratropical Northern Hemisphere $\left(20^{\circ}-90^{\circ} \mathrm{N}\right)$ in two fundamentally different climate states, the PI and the LGM. The aim of this paper is to document how SLP variability and its leading mode might have changed in a glacial climate, and how this change could affect proxy data. Our study attempts to elucidate issues associated with the assumption of a stationary relationship between climate and proxy signals. The goals are to better understand the spatial scale represented by proxy records and the influence of changed SLP variability on those proxy records. Finally, we try to identify the locations that are able to detect a substantial amount of large-scale variability in both climate states - preferred proxy locations where a straightforward comparison of the glacial and modern states might be possible.

This work is structured as follows: Sect. 2 gives a description of the coupled models used and the boundary conditions for the PI and LGM climates; Sect. 3 presents the changes in the magnitude and spatial pattern of SLP variability in the Northern Hemisphere $(\mathrm{NH})$ and the distribution of this variability over the seasonal cycle; Sect. 4 discusses the influence of atmospheric circulation changes on the signal recorded in proxies. Conclusions are presented in Sect. 5.

\section{Data and methods}

We analyze output belonging to the Paleoclimate Modelling Intercomparison Project Phase II (PMIP2, http://pmip2.lsce. ipsl.fr). Results are based on the Community Climate System Model 3.0 (CCSM3), the Institut Pierre-Simon Laplace model (IPSL), the Hadley Centre Coupled Model version 3 (HadCM3M2) and the Model for Interdisciplinary Research on Climate version 3.2 (MIROC3.2). The other two coupled models available in the PMIP2 database (Flexible Global Ocean-Atmosphere-Land System model, FGOALS and Centre National de Recherches Mtorologiques, CNRM) have not been considered because of inconsistencies between their representation of the PI climate and observation-based reanalyses.

The horizontal resolution in the atmosphere varies slightly between models, but has a nominal grid spacing of $300 \mathrm{~km}$ or T42 (Table 1). Boundary conditions for the two climate states (PI and LGM) follow the protocol established by PMIP2. In the PI simulations, the orbital configuration is set to $1950 \mathrm{AD}$ values, the greenhouse gases correspond to $1750 \mathrm{AD}$ and vegetation is prescribed to a static modeldependent present day distribution. In the LGM simulations, the orbital configuration is set to $21 \mathrm{ka}$, greenhouse gas concentrations are lower and result in a $2.8 \mathrm{Wm}^{-2}$ decrease in radiative forcing (Braconnot et al., 2007), the static vegetation is as in the PI simulations and the ice sheets are prescribed according to the ICE-5G reconstruction (Peltier, 2004).

For each model's equilibrium simulation of the LGM and PI climates, 100 years of monthly post-spinup SLP, temperature and precipitation data from $20^{\circ}-90^{\circ} \mathrm{N}$ are analyzed. The results presented here are based on monthly anomalies from the seasonal cycle. The variability in the resultant time series is concentrated at interannual time scales and is hereafter referred to as interannual variability. Standard Empirical Orthogonal Function (EOF)/Principal Component (PC) analysis has been used to assess the leading mode of SLP variability in the North Atlantic. All differences discussed in this study are significant at the $1 \%$ confidence level, unless otherwise noted. The Atlantic sector is defined as $20^{\circ}-90^{\circ} \mathrm{N}$, $120^{\circ} \mathrm{W}-45^{\circ} \mathrm{E}$ using the Rocky Mountains and the Urals as boundaries, but the results presented here are not strongly sensitive to the particular definition of the sector.

\section{Variability in the atmospheric circulation}

This section is divided into three parts. The first describes differences in interannual Northern Hemisphere SLP variability and the leading patterns of North Atlantic SLP variability between LGM and PI simulations. The second describes the distribution of interannual SLP variability and the leading mode of SLP variability over the seasonal cycle. The last discusses reasons for the differences in SLP variability, not only between the LGM and PI simulations from a given 
Table 1. Spatial resolution of PMIP2 model components.

\begin{tabular}{lcccc}
\hline Model & Atm. Horiz. Resol. & Atm. Vert. Resol. & Ocean Horiz. Resol. & Ocean Vert. Resol. \\
\hline CCSM3 & T42 & 26 levels & $1^{\circ} \times 1^{\circ}$ & 40 levels \\
IPSL & $3.75^{\circ} \times 2.5^{\circ}$ & 19 levels & $2^{\circ} \times 0.5^{\circ}$ & 31 levels \\
HadCM3M2 & $3.75^{\circ} \times 2.5^{\circ}$ & 19 levels & $1.25^{\circ} \times 1.25^{\circ}$ & 20 levels \\
MIROC3.2 & $\mathrm{T} 42$ & 20 levels & $1.4^{\circ} \times 0.5^{\circ}$ & 43 levels \\
\hline
\end{tabular}

Table 2. LGM-PI changes in interannual variability of SLP in the Northern Hemisphere ( $\sigma_{N H}$ of SLP) and in the North Atlantic ( $\sigma_{N A}$ of SLP); fraction of variance explained by the leading $\operatorname{EOF}\left(\lambda_{1}\right)$; amount of raw variability explained by the leading EOF in standard deviation units $\left(\sqrt{\lambda_{1} \sigma_{N A}^{2}}\right)$; and the amplitude of the seasonal cycle of Northern Hemisphere SLP variability (seasonal cycle of $\sigma_{N H}$ ). Standard deviation changes that are not significant at $1 \%$ confidence level are in bold.

\begin{tabular}{lccccc}
\hline LGM - PI: & $\sigma_{N H}$ of SLP & $\sigma_{N A}$ of SLP & $\lambda_{1}$ & $\sqrt{\lambda_{1} \sigma_{N A}^{2}}$ & Seasonal cycle of $\sigma_{N H}$ \\
\hline CCSM3 & $-10 \%$ & $-11 \%$ & $-34 \%$ & $-28 \%$ & $-38 \%$ \\
IPSL & $-6 \%$ & $-6 \%$ & $-29 \%$ & $-21 \%$ & $-30 \%$ \\
HadCM3M2 & $-16 \%$ & $-16 \%$ & $-5 \%$ & $-18 \%$ & $-25 \%$ \\
MIROC3.2 & $\mathbf{+ 3 \%}$ & $+9 \%$ & $-16 \%$ & $0 \%$ & $-19 \%$ \\
\hline
\end{tabular}

model, but also between models for simulations of a given climate. Both the ERA-40 (Uppala et al., 2005) and NCEPNCAR (Kistler et al., 2001) reanalyses are used to validate general characteristics of the PI model results. A set of figures analogous to the model results in Sect. 3, but using the ERA-40 reanalysis, is shown in Appendix A. Both reanalyses are used to validate model-based interpretations in Sect. 4.

\subsection{Spatial distribution of SLP variance}

In three out of four models, the interannual variability of $\mathrm{NH}$ SLP is reduced in the LGM simulations compared to the PI simulations (Fig. 1). The differences in standard deviation $(\sigma)$ are largest in high latitudes, especially along Greenland's east coast, over the northeastern Pacific Ocean along the coast of Alaska, and over the Barents Sea (Fig. 1, right panels). Averaged over the extratropical NH, the model simulations exhibit a significant LGM decrease in SLP standard deviation compared to the PI (Fig. 1), ranging from $6 \%$ in IPSL to $16 \%$ in HadCM3M2. MIROC3.2 shows a small and not significant increase in SLP standard deviation in the LGM simulation. Reductions in LGM interannual variability are also simulated for the free troposphere $(500 \mathrm{hPa}$ geopotential heights, not shown) and Li and Battisti (2008) documented an analogous decrease in jet level wind variability in CCSM3's LGM simulation.

The leading mode of North Atlantic SLP variability from EOF analysis (Fig. 2) shows that an NAO-like feature is the leading mode of North Atlantic SLP variability in the LGM simulations, but it is less well-defined and represents less interannual variance than in the PI. The fraction of variance associated with the leading LGM mode $\left(\lambda_{1}\right)$ is reduced in all models (Fig. 2 and Table 2). The CCSM3 exhibits the largest change in $\lambda_{1}$ from the PI (38\%) to LGM (25\%) simulation and $\lambda_{1}$ values are similar to the extratropical $\mathrm{NH}$ winter calculations reported by Otto-Bliesner et al. (2006) in the same simulations.

There is an LGM decrease of between 18 and $28 \%$ in the interannual SLP standard deviation associated with the leading mode $\left(\sqrt{\lambda_{1} \sigma_{N A}^{2}}\right)$ for each model except MIROC3.2. For the three consistent models, the LGM decrease results from combined reductions in both interannual SLP variance $\left(\sigma_{N A}^{2}\right)$ and the fraction of variance explained by the leading mode of SLP variability (see Fig. 2 and Table 2). There is no change in the interannual SLP standard deviation explained by the leading mode in MIROC3.2, due to compensating changes in SLP variance and the fraction of variance explained by the leading mode.

The leading mode of North Atlantic LGM SLP variability is qualitatively similar to that in the PI. The spatial pattern in each simulation is an opposing dipole of SLP anomalies that straddle the simulation's climatological-mean low in SLP. Both the centers of action and the related SLP gradient associated with the leading mode are weaker in the LGM simulations from two models (CCSM3 and IPSL) and are comparable to the PI leading mode in the other two models (HadCM3M2 and MIROC3.2). There is no model-to-model agreement on the absolute location of the centers of action, but each model simulates a shift southward/southeastward of the EOF1 pattern at the LGM relative to the PI. In two models (CCSM3 and IPSL), the southern lobe moves southeastward towards the Mediterranean Sea, qualitatively similar to what was seen in the studies of Justino and Peltier (2005) and Peltier and Solheim (2002). 

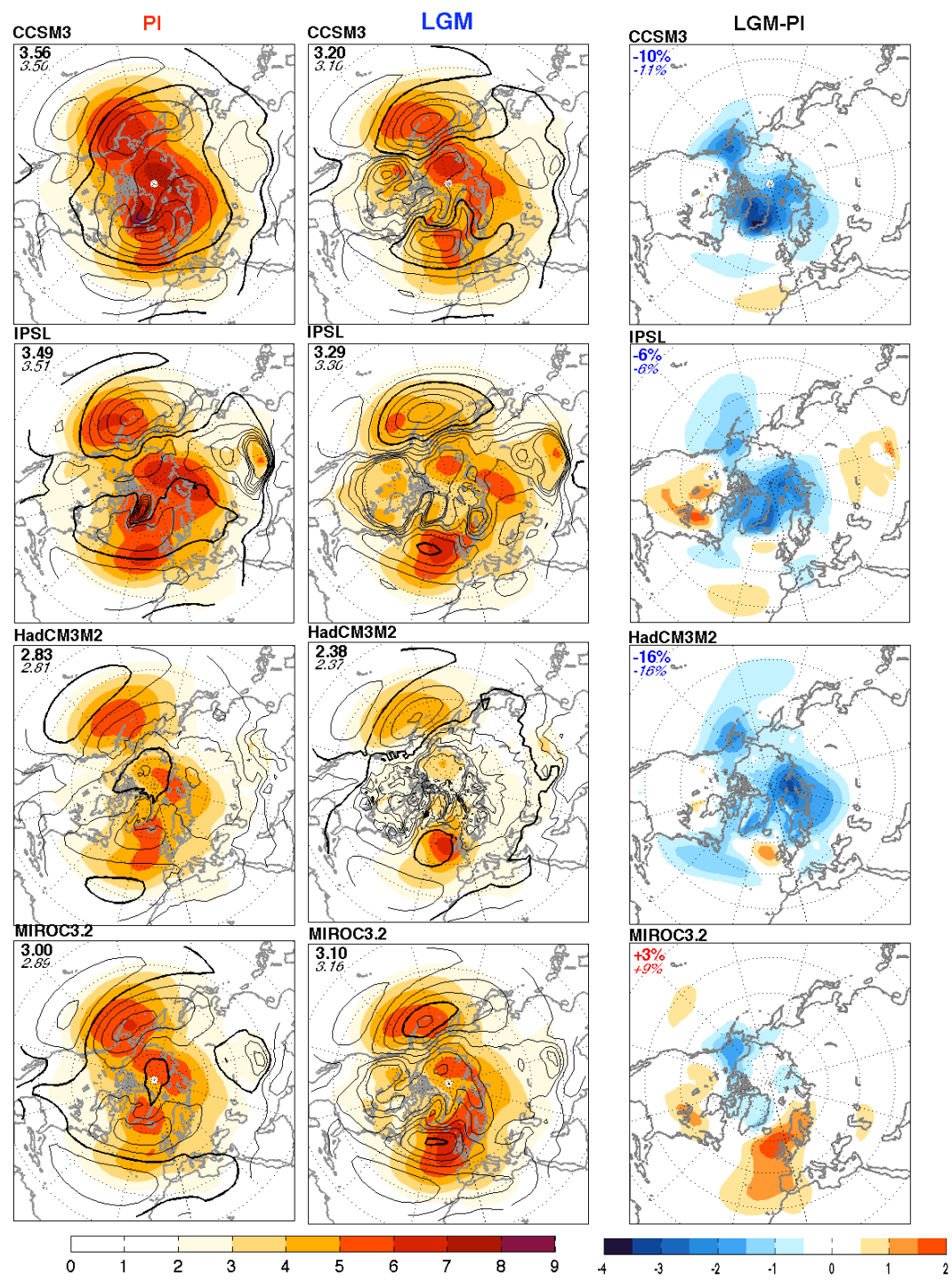

Fig. 1. The mean (contours: $4 \mathrm{hPa}$ interval from 1000 to $1040 \mathrm{hPa}$; higher values omitted for clarity; bold contour denotes $1016 \mathrm{hPa}$ ) and standard deviation (colored shading: hPa) of monthly SLP averaged over all months in simulations of PI (left) and LGM (center) climate. Numbers show the SLP standard deviation area-averaged over the Northern Hemisphere $\left(\sigma_{N H}\right.$ in bold $)$ and over the North Atlantic $\left(\sigma_{N A}\right.$ in italic). Differences (LGM-PI) are shown in the right panels.

\subsection{Seasonal cycle of variability}

Reductions in interannual SLP variability within the LGM simulations relative to the PI simulations are not evenly distributed throughout the year. Figure 3 shows the seasonal cycle of interannual SLP standard deviation for all model simulations. LGM reductions are concentrated in winter, the season with the most interannual variability in each model's simulation of both climates. In summer and early fall, changes are smaller and often not statistically significant. The leading mode of SLP variability (Fig. 2) exhibits reductions in associated variance that are also concentrated in winter (Fig. 4), suggestive of a dynamically consistent model response during the most active season for North Atlantic variability.
The seasonal cycle of interannual SLP variability is altered in the LGM relative to the PI simulations as a result of the greater wintertime reductions. (Fig. 3, Table 2). Simulations of the LGM climate exhibit not only less interannual variability within each month, but also less of a change in interannual variability across the seasonal cycle. In other words, interannual summer variability is more similar to interannual winter variability during the LGM. Note that the weaker seasonal cycle is also seen further aloft in flow-related fields such as 500-hPa geopotential height (not shown), suggesting that these changes in atmospheric variability are dynamically driven. 


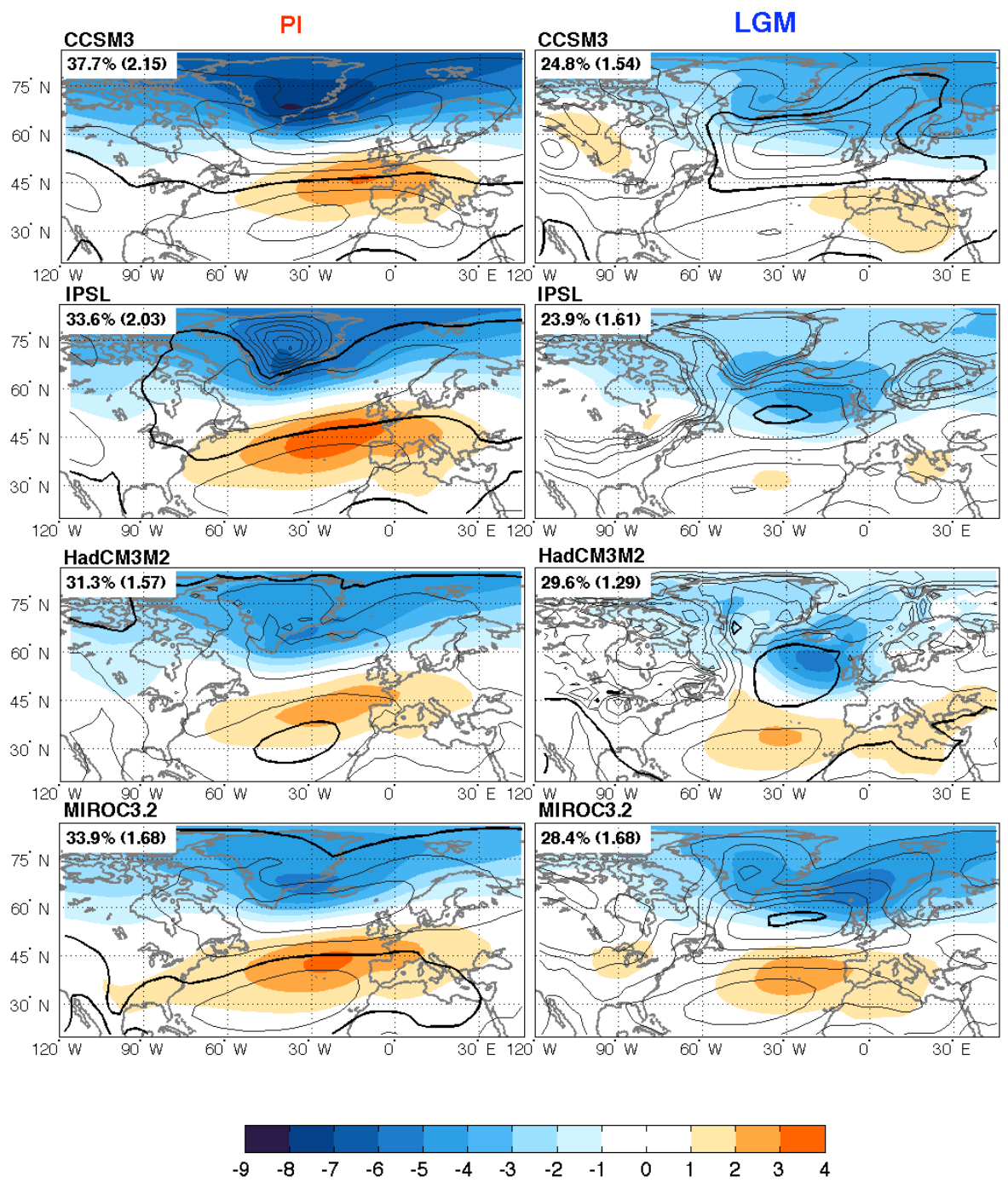

Fig. 2. Leading EOF of monthly SLP anomalies (colored shading: hPa/standard deviation of PC) and SLP climatology (contours: $4 \mathrm{hPa}$ interval from 1000 to $1040 \mathrm{hPa}$; higher values omitted for clarity; bold contour denotes $1016 \mathrm{hPa}$ ) in the North Atlantic sector (all months) for the PI and LGM simulations. Numbers show the amount of variance explained by the first mode both as a percentage of the total variance $\left(\lambda_{1}\right)$ and as a standard deviation in $\mathrm{hPa}\left(\sqrt{\lambda_{1} \sigma_{N A}^{2}}\right)$.

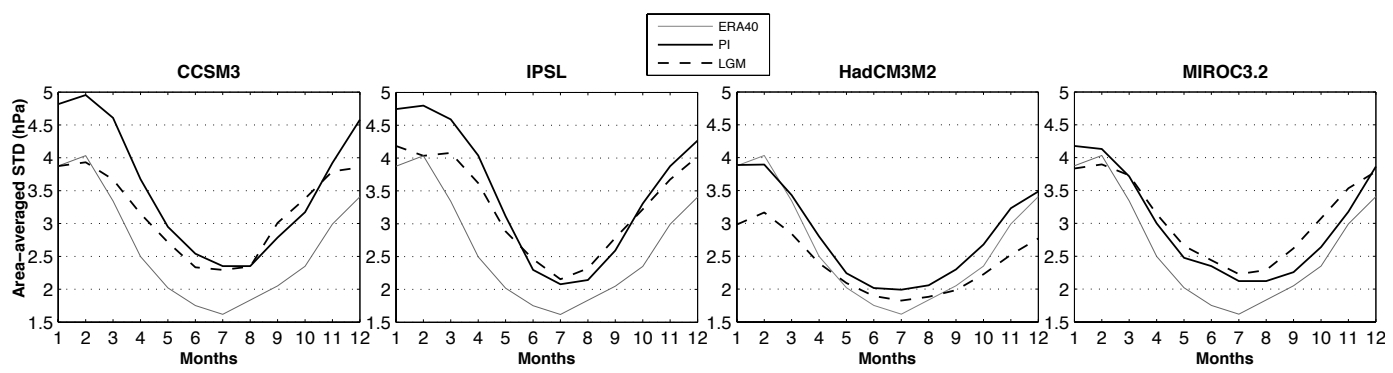

Fig. 3. Seasonal cycle of interannual SLP standard deviation over the Northern Hemisphere in the PI and LGM simulations, and for the ERA-40 reanalysis 1957-2002. 

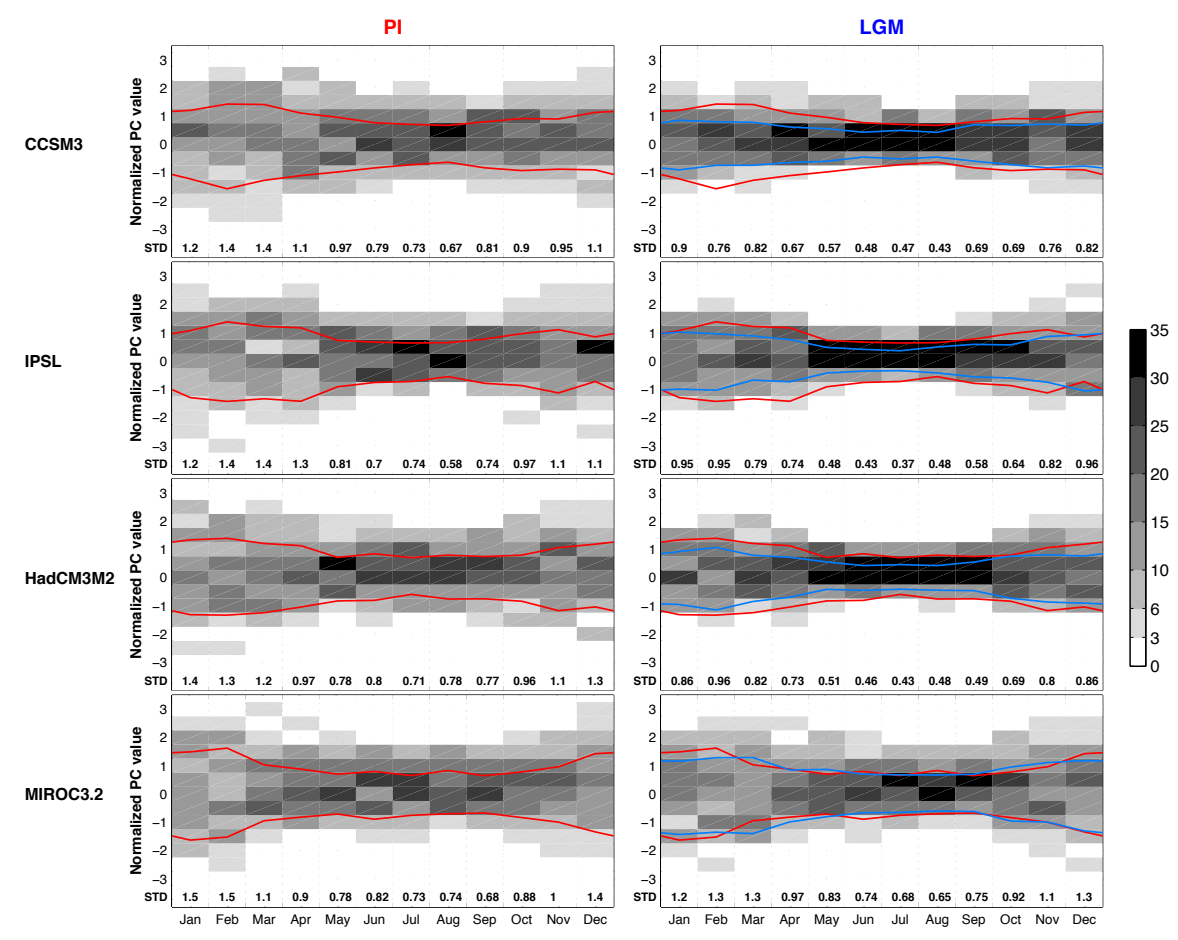

Fig. 4. The seasonality of NAO-like variability in LGM and PI simulations. For each month, the shading in each 0.5 standard deviation bin ( $y$-axis) represents the occurrence frequency of the NAOlike PC1 within that interval. The monthly PC1 time series from both simulations of a given model is normalized by the standard deviation of the annually averaged PC1 from the models PI simulation. This standardization enables a comparison between the models simulation of the two climate states. The spread of the normalized PC1s in a given month is an indication of the interannual variability in the leading mode for that month: a wider spread suggests that the amplitude of NAO-like oscillations is increased. The standard deviations of the PC in these normalized units are indicated along the $x$-axis for each month and are marked by the lines (red for PI, blue for LGM).

\subsection{Discussion}

The LGM simulations show a significant reduction in interannual SLP variance and a weakening of the leading mode of SLP variability relative to the PI simulations. These changes in atmospheric variability must be due to differences in radiative forcing, land/ocean geometry, land ice, and their combined influence on surface properties such as sea surface temperature and sea ice distribution. However, the details of these LGM-PI changes vary considerably from model to model, making it difficult to draw clear conclusions. In this section, we present results of some sensitivity experiments designed to address these issues, but the analyses and experiments required for a complete treatment of what causes the LGM-PI and model-to-model differences in SLP variability are beyond the scope of this study.

The sensitivity experiments were performed with the Community Atmosphere Model CAM3 (Collins et al., 2006), the atmospheric component of the CCSM3 coupled model. CAM3 is able to reproduce the climatology and variability of the full CCSM3 for each climate given the appropriate forcings: insolation, land mask, ice sheets (topography and albedo), greenhouse gas concentrations, as well as sea sur- face temperature (SST) and sea ice fields from the ocean component of the coupled model (Figs. 5 and 6). The experiments, with their forcing setups, are listed in Table 3.

First, we address the differences between the LGM and PI climates. From the point of view of the atmospheric model, the key forcing changes are: (a) ice sheets over North America and Eurasia (topography and albedo forcing), (b) reduced greenhouse gas concentrations, and (c) surface properties, including SST and sea ice. A secondary factor is insolation, which is only slightly different between the LGM and PI simulations. Insolation, ice sheets and greenhouse gases are specified as true external boundary conditions and thus identical in all the PMIP2 simulations; SST and sea ice are calculated internally in the fullycoupled simulations and thus differ from model to model, especially in the LGM simulations. To evaluate the relative importance of the ocean forcing (SST and sea ice) and the external forcing (insolation, ice sheets and greenhouse gases), we compare the full PI (PIbc+PIccsmSST) and LGM (LGMbc+LGMccsmSST) experiments to two sensitivity experiments (PIbc+LGMccsmSST and LGMbc+PIccsmSST) where we mix PI/LGM ocean and PI/LGM external forcing (Table 3). 


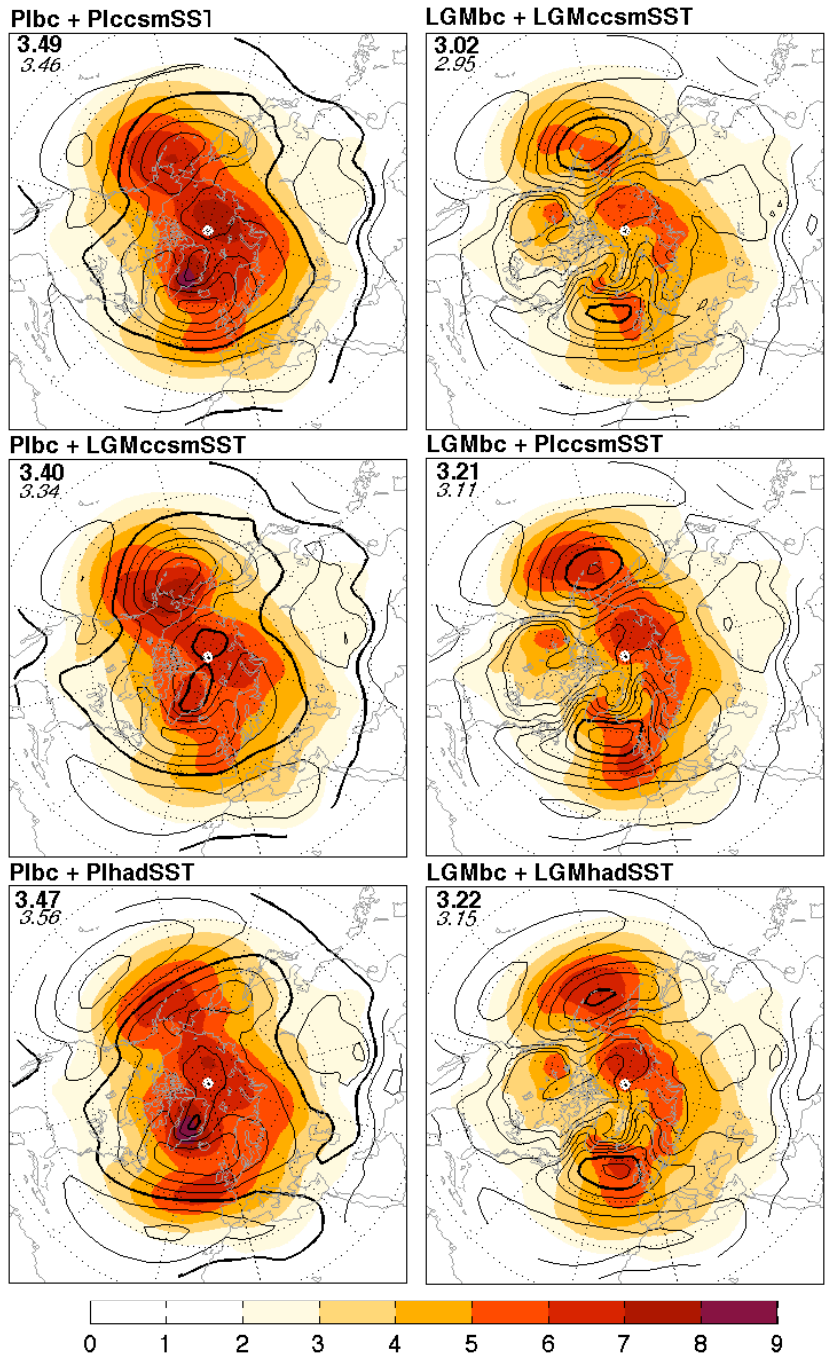

Fig. 5. The mean (contours: $4 \mathrm{hPa}$ interval from 1000 to $1040 \mathrm{hPa}$; higher values omitted for clarity; bold contour denotes $1016 \mathrm{hPa}$ ) and standard deviation (colored shading: hPa) of monthly SLP averaged over all months in the sensitivity experiments. Numbers show the SLP standard deviation area-averaged over the Northern Hemisphere ( $\sigma_{N H}$ in bold) and over the North Atlantic ( $\sigma_{N A}$ in italic).

The sensitivity experiment with LGM external forcing (LGMbc+PIccsmSST) shows a mean SLP field that resembles the mean state of the full LGM simulation (LGMbc+LGMccsmSST), even when forced by PI SST/sea ice (Fig. 5). The leading mode of SLP variability in each LGM external forcing experiment is also quite similar to the full LGM simulation (Fig. 6), but the pattern of internannual SLP variability is different in each experiment (Fig. 5). The experiments using PI external forcing (PIbc+LGMccsmSST) have mean SLP distributions that resemble those of the full PI simulation, even when forced by LGM ocean forcing (SST and sea ice) (Fig. 5). The leading mode of SLP variability and its explained variance are also comparable to the full
Table 3. Boundary conditions (insolation, ice sheet and greenhouse gases) and SST and sea ice forcings used for the sensitivity experiments.

\begin{tabular}{lcc}
\hline Experiment & Boundary Conditions (bc) & SST + Sea Ice. \\
\hline PIbc+LGMccsmSST & PI & LGM CCSM3 \\
LGMbc+PIccsmSST & LGM & PI CCSM3 \\
PIbc+PIhadSST & PI & PI HadCM3M2 \\
LGMbc+LGMhadSST & LGM & LGM HadCM3M2 \\
\hline
\end{tabular}

PI simulation (Fig. 6), while the pattern of interannual SLP variance is different in all three experiments (Fig. 5). In all the sensitivity experiments the leading mode variance is not consistently affected by the SST and sea ice (not shown).

There are a number of ways in which changes in the external forcing can affect atmospheric variability. We focus our discussion on ice sheets and greenhouse gases as these exhibit larger LGM-PI differences than insolation (see Fig. 1 in Otto-Bliesner et al., 2006). The large Laurentide ice sheet covering North America creates an upstream-blocking situation that may be related to a stronger, but less variable, Atlantic jet at the LGM relative to the PI climate ( $\mathrm{Li}$ and Battisti, 2008; Donohoe and Battisti, 2009). The reduced variance associated with the leading mode of SLP variability (Fig. 4) is broadly consistent with this change in upper-level jet variability; it could also be linked to the lower greenhouse gas concentrations at the LGM, much as the recent increase in NAO variance is thought be linked to external factors such as increases in greenhouse gas concentrations and/or changes in surface properties (Feldstein, 2002). Our results suggest that surface properties (SST and sea ice), are not important for determining the leading mode of SLP variability, but have some influence on the magnitude and pattern of interannual SLP variability. These findings are qualitatively consistent with the study of Kushnir et al. (2002), in which it is demonstrated that atmospheric variability is more affected by internal atmospheric processes than by the extratropical ocean. Other studies suggest that sea ice anomalies can affect atmospheric variability, particularly the phase and amplitude of the NAO (Deser et al., 2000; Seierstad and Bader, 2008).

Second, we address the fact that while the PMIP2 coupled models show a consistent response to PI forcings, this is not the case for LGM forcings (Figs. 1 and 2). A possible reason is that the PMIP2 models produce similar SST and sea ice distributions in the PI climate but not at the LGM. A simple test is to impose the ocean forcing (SST/sea ice) produced by one of the other models on CAM3. We choose the HadCM3M2 ocean forcing because it is most dissimilar to those from CCSM3 (experiment LGMbc+LGMhadSST). The resulting SLP field is more like that of the CCSM3based simulation (LGMbc+LGMccsmSST) than that of the fully coupled HadCM3M2 simulation, both in terms of interannual variability (Figs. 5 and 1) and its leading mode of SLP variability (Figs. 6 and 2). This suggests that the 

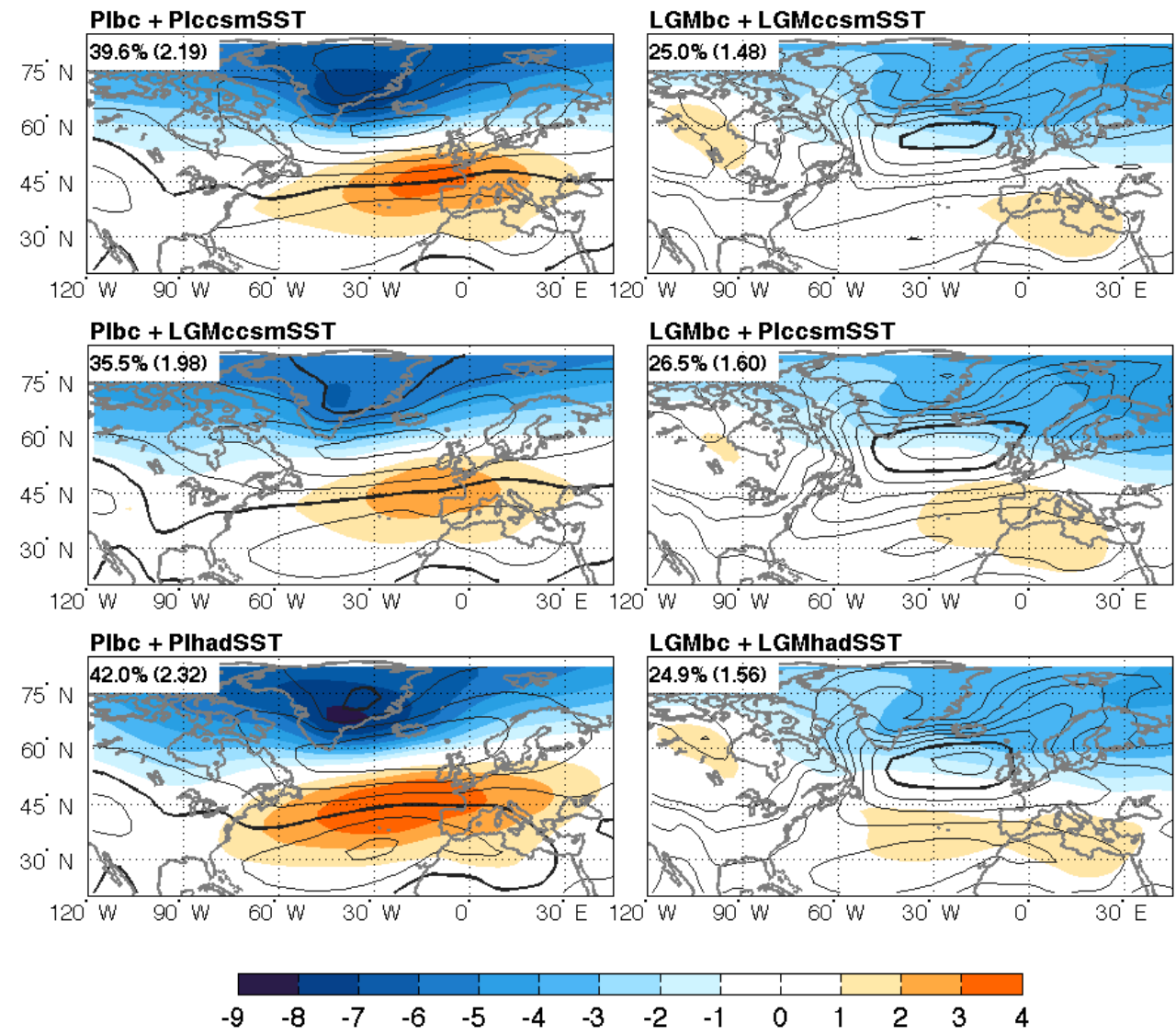

Fig. 6. Leading EOF of monthly SLP anomalies (colored shading: hPa/standard deviation of PC) and SLP climatology (contours: $4 \mathrm{hPa}$ interval from 1000 to $1040 \mathrm{hPa}$; higher values omitted for clarity; bold contour denotes $1016 \mathrm{hPa}$ ) in the North Atlantic sector (all months) for the sensitivity experiments. Numbers show the amount of variance explained by the first mode both as a percentage of the total variance $\left(\lambda_{1}\right)$ and as a standard deviation in $\mathrm{hPa}\left(\sqrt{\lambda_{1} \sigma_{N A}^{2}}\right)$.

atmosphere model CAM3 produces similar SLP variability, regardless of the exact ocean forcing used, consistently with the results of the aforementioned sensitivity studies (PIbc+LGMccsmSST and LGMbc+PIccsmSST). A likely explanation is that the atmosphere models respond differently to the same external forcing because of differences in the PI zonal mean flows simulated by the two coupled models, or perhaps because of differences in physics internal to the two atmospheric models (e.g., differences in the parametrization of gravity wave drag). We can not rule out, however, that the atmosphere model used in the HadCM3M2 is more sensitive to the prescription of the ocean forcing than is the atmospheric model used in the CCSM3, and the differences in the LGM mean state and variability simulated by the HadCM3M2 and the CCSM3 are symptomatic of the differences in the SST and sea ice simulated in these two coupled models.

In summary, our findings suggest that the differences between LGM and PI simulations in CCSM3 are due to the external forcing, with the ocean forcing playing a minor role.
Reduced interannual variability at the LGM relative to the PI is a consistent change observed in several of the models, and hence considered a robust model result. The exact amount and spatial characteristics of this variability appear to be model-specific.

\section{Paleoclimate implications}

Changes in the mean and variability of atmospheric circulation, in the leading modes, or in the seasonality of any of these components are interesting from a dynamical standpoint, but they could also have a demonstrable impact on the signal recorded in climate proxies.

The reconstruction of past climate from proxies is based on the idea that natural archives record variations in temperature, precipitation, or some combination of these and other environmental conditions. For simplicity, variability in surface temperature and precipitation are referred to as "surface climate variability". Reconstructions of surface climate 
Table 4. Correlations between winter season surface air temperature and PC1 of sea level pressure in the North Atlantic sector for the four locations indicated in Figs. 7 and 8. Correlations values from ERA-40 and NCEP/NCAR reanalysis are shown for comparison. The four locations have been chosen as reference points: the locations on Greenland have been widely used for climate reconstructions; the other two land points are areas where the models agree that temperature and/or precipitation variability are coherently related to the leading mode of variability in both climates.

\begin{tabular}{lcccccc}
\hline WINTER Season $($ Temp. $)$ & ERA-40 & NCEP/NCAR & \multicolumn{2}{c}{ CCSM3 } & \multicolumn{2}{c}{ HADCM3M2 } \\
\hline & $1957-2002$ & $1957-2002$ & PI & LGM & PI & LGM \\
$\triangle$ NASA-U $\left(74^{\circ} \mathrm{N}, 50^{\circ} \mathrm{W}\right)$ & -0.58 & -0.68 & -0.39 & -0.61 & -0.57 & 0.33 \\
$\circ$ Summit $\left(73^{\circ} \mathrm{N}, 37^{\circ} \mathrm{W}\right)$ & -0.54 & -0.63 & -0.15 & -0.60 & -0.45 & -0.08 \\
$\diamond$ Labrador $\left(52^{\circ} \mathrm{N}, 60^{\circ} \mathrm{W}\right)$ & -0.75 & -0.77 & -0.46 & -0.48 & -0.65 & -0.55 \\
$\star$ Norway $\left(60^{\circ} \mathrm{N}, 6^{\circ} \mathrm{E}\right)$ & 0.71 & 0.75 & 0.61 & 0.33 & 0.77 & 0.70 \\
\hline
\end{tabular}

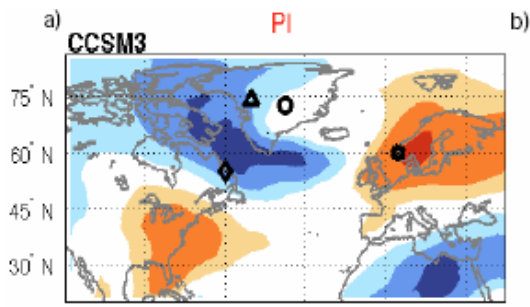

b)
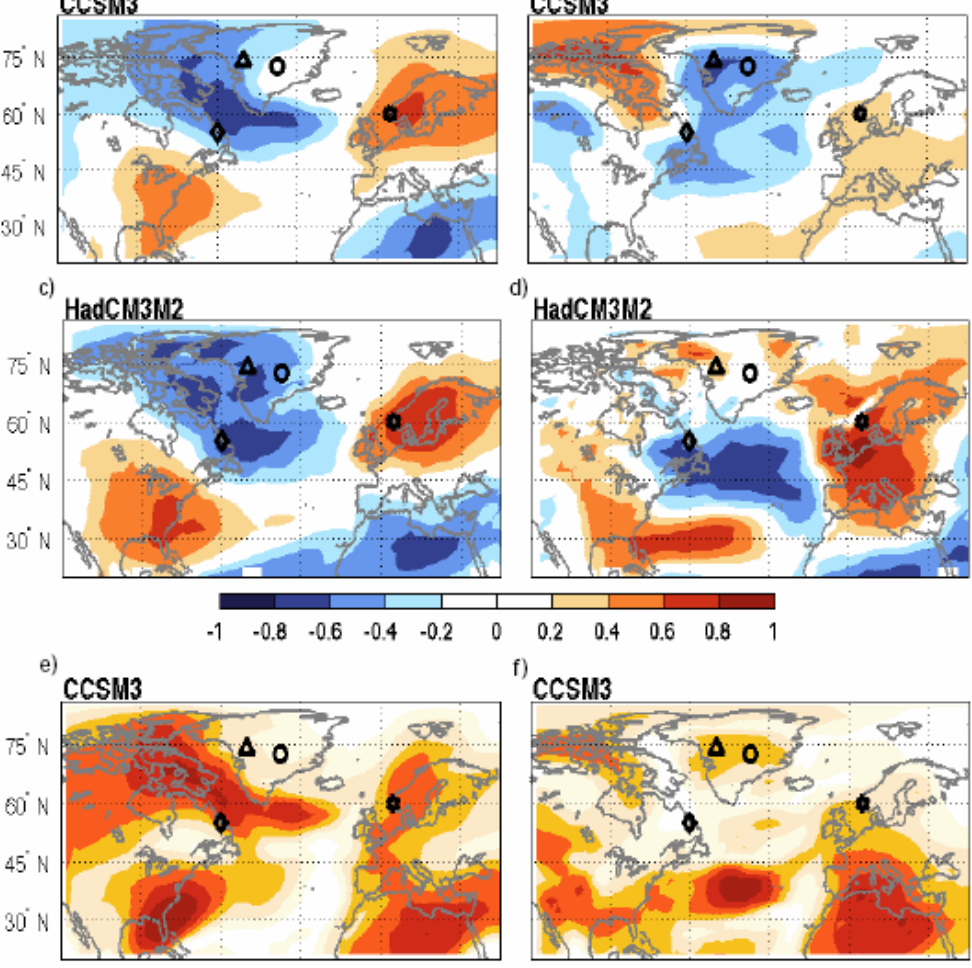

d) $\mathrm{HadCM} 3 \mathrm{M2}$

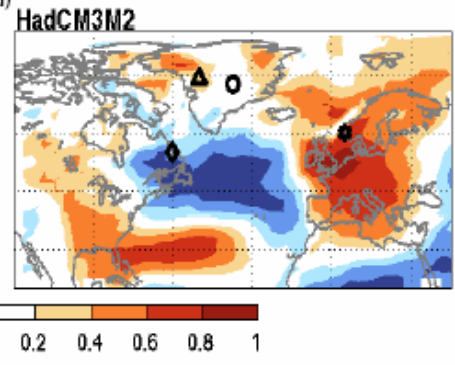

f) $\operatorname{ccs} 3$
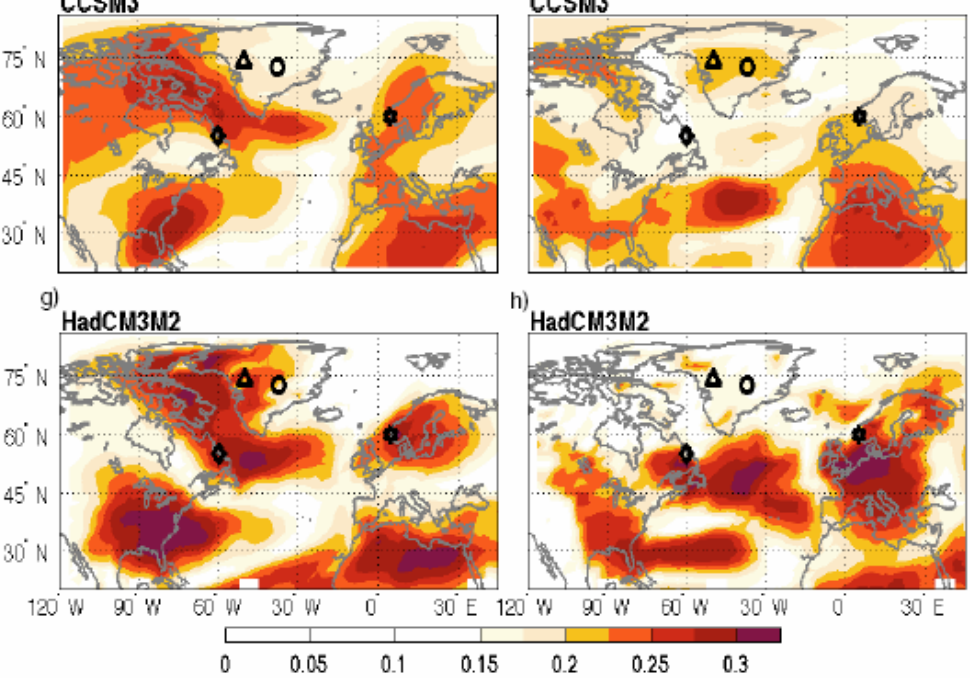

Fig. 7. PI and LGM correlations between North Atlantic winter surface air temperature (November to April) and PC1 (NAO-like index) for CCSM3 (a), (b) and HadCM3M2 (c), (d). An indicator of temperature coherence in the sector for CCSM3 (e), (f) and HadCM3M2 (g), (h): the value at each point is the absolute value of the area-averaged correlation between temperature at that point and the rest of the North Atlantic basin. The results from the IPSL model are similar to CCSM3 and the results from MIROC3.2 are similar to HadCM3M2. Only the winter months are included, as this is when the NAO-like signal is strongest. When including all months the result is the same, but with slightly weaker correlation patterns. Markers indicate the locations used in Table 4. 


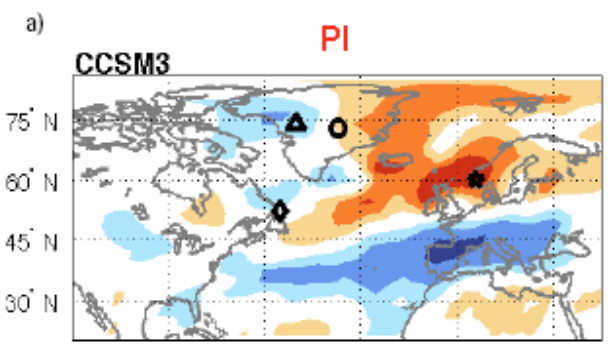

b) LGM

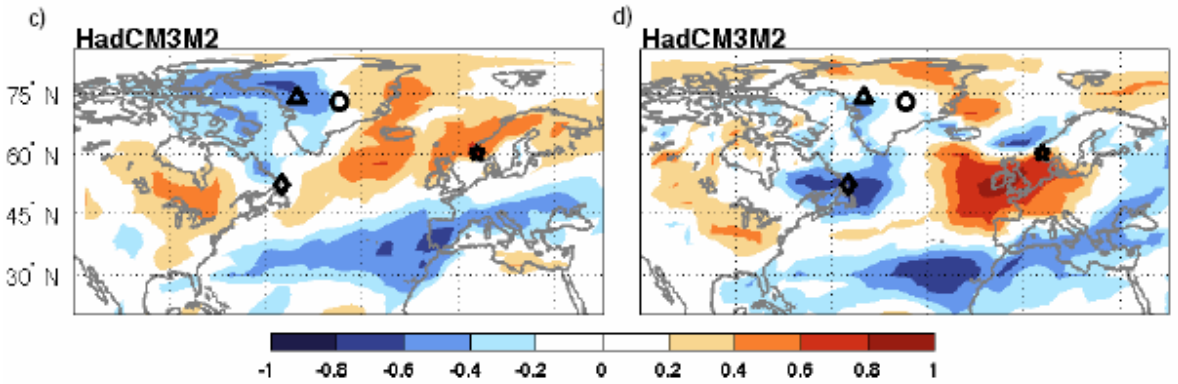

e) $\operatorname{ccsm} 3$

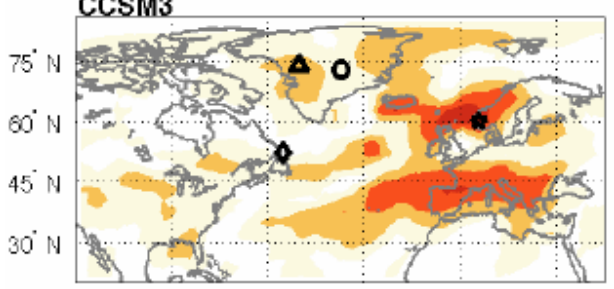

f) $\operatorname{ccs} 33$

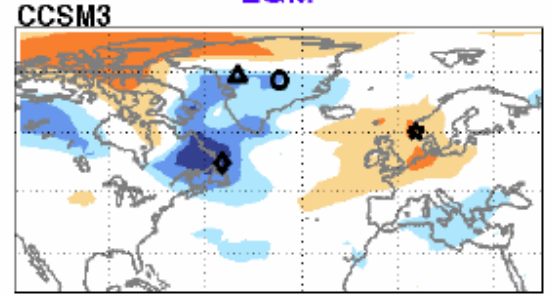

cCSM3

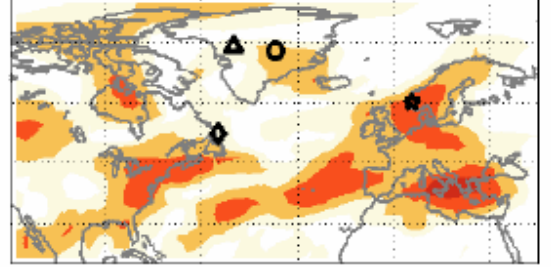

g)

HadCM3M2

$75^{\circ} \mathrm{N}-40$
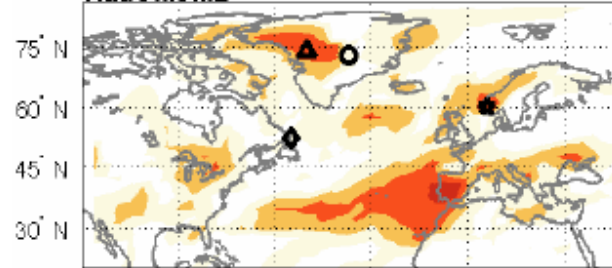

h) HadCM3M2

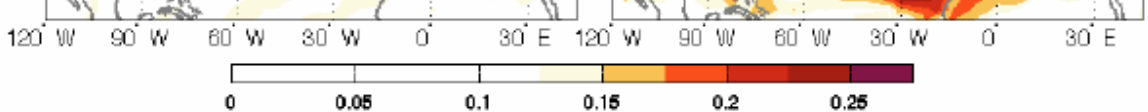

Fig. 8. Same as Fig. 7 for precipitation.

variability over recent centuries have been performed using archives such as tree rings (e.g. Glueck and Stockton, 2001), ice cores (e.g. Appenzeller et al., 1998) and pollen in lake sediments (e.g. Voigt et al., 2008). A common goal in selecting proxy sites is to find locations where local variability represents larger spatial scales. For example, in the present climate, surface temperature and precipitation at many locations in the Atlantic sector are coherently coupled to the NAO (e.g. Hurrell, 1995), such that any site able to capture the leading mode of SLP variability (NAO) will also capture dynamically linked aspects of regional climate variability.

There have been studies attempting to reconstruct regional climate variability in different climate states from a limited number of locations (e.g. Allen et al., 1999; Bakke et al., 2005; Bahr et al., 2006). Unfortunately, the same geographic site may record a qualitatively different mixture of mean and variance contributions in different climates. For example, the of atmospheric variability could change, resulting in a center of action shifting towards or away from a proxy site. Alternatively, a change in seasonality (i.e., in how variability is distributed throughout the year) could affect proxies that record signals preferentially at certain times of the year.

To help assess the impact of such changes on the structure of surface climate variability in different climate states, we construct coherence maps for temperature and precipitation from the simulation of PI and LGM climate (Figs. 7-8 panels e to $h$ ). In these maps, higher values indicate that the variability at that location has higher coherance with variability throughout the North Atlantic. In the PI simulations, the models show a similar and coherent pattern of variability for 

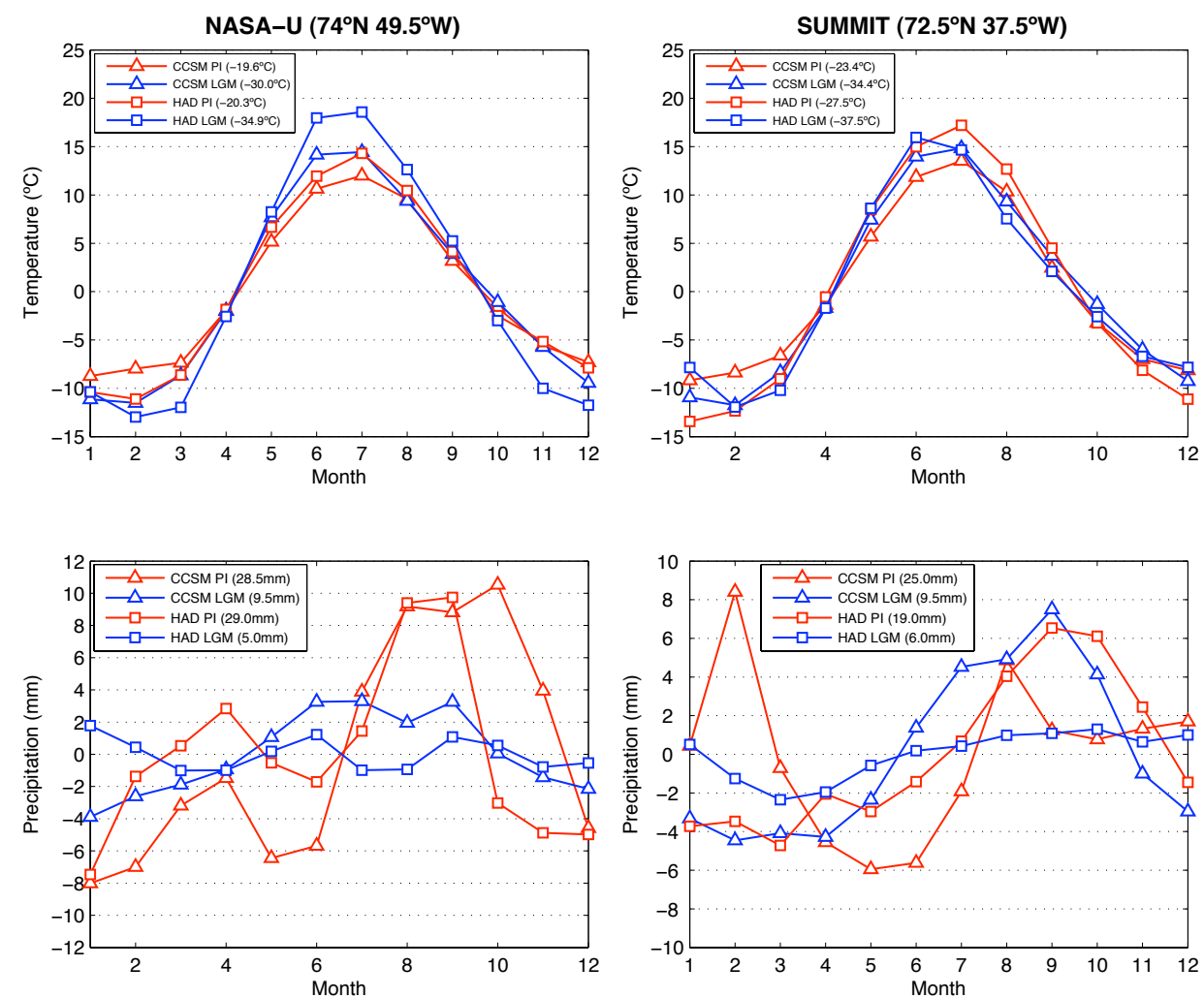

Fig. 9. PI and LGM seasonal cycle for temperature (upper panels) and precipitation (lower panels) in CCSM3 and HadCM3M2 for two locations in Greenland (NASA-U (left) and Summit (right)). The annual mean has been subtracted to facilitate comparison between climate states and models.

PI

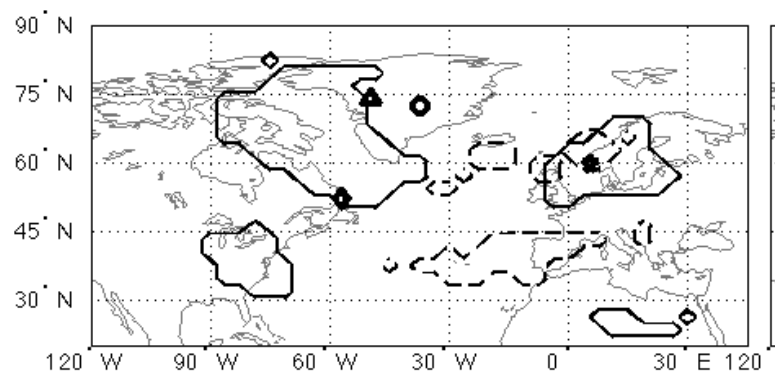

LGM

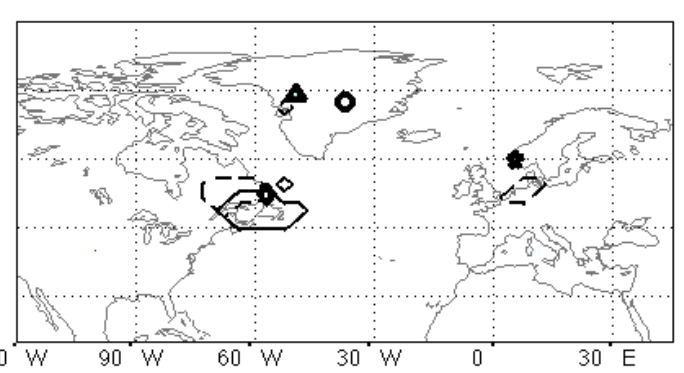

Fig. 10. Solid (dashed) lines represent the areas where the correlation between temperature (precipitation) and the PC1 of the SLP for all the models is greater than 0.4 in absolute value in the PI and LGM simulations.

both temperature and precipitation (Figs. 7-8 panels e and g). In contrast, the pattern of variability during the LGM is model dependent, but in each model different from that in the PI simulations (Figs. 7-8 panels $\mathrm{f}$ and $\mathrm{h}$ ).

The link between surface climate variability and the leading mode of SLP variability can also be altered in a different climate state: that is, the relationship between surface climate and the leading mode of SLP variability can change. Correlation statistics between surface temperature or precipitation and the temporal series of the leading mode of SLP variability (PC1) are shown in Figs. 7 and 8 (panels a to d) for both the PI and LGM climate states. In the PI simulations, maxima in the coherence maps are collocated with maxima or minima in the PC1 correlation maps. The pattern match between the coherence and PC1 correlation maps in the PI simulations suggests that the leading mode of SLP variability (NAO) is the dominant control over North Atlantic surface temperature and precipitation variability, as has been shown by Hurrell (1995) in observations. In the LGM simulations, the models do not agree about the link 
between the leading mode of SLP variability and surface climate variability. Two behaviors emerge from the model analysis: (1) for CCSM3, surface climate variability in the North Atlantic is not dominated by the leading (NAO-like) mode of SLP variability (compare panels $b$ and $f$ in Figs. 7 and 8); (2) for HadCM3M2, surface climate is more strongly linked to NAO-like variability (compare panels $\mathrm{d}$ and $\mathrm{h}$ in Figs. 7 and 8). CCSM3 shows a much larger reduction in the strength of NAO-like variability relative to HadCM3M2 in the LGM simulations (Fig. 2 and Table 2), which could be the reason for the disagreement between the models.

Figures 7 and 8 show that because of changes in the link between the of leading mode of SLP variability and surface climate, a location might be able to record the leading mode but not reflect regional surface climate variability at the LGM. As one example, regional variability may be disconnected from the leading mode of SLP, as seen for Summit, Greenland in the CCSM3 (compare panels $b$ and $\mathrm{f}$ in Figs. 7 and 8). Another possibility is that because of the southward shift of the leading mode of SLP variability at the LGM, Greenland might be situated at the flank of the dominant North Atlantic atmospheric variability in a glacial climate. An example of this is that surface climate at the Summit of Greenland in HadCM3M2 reflects a combination of both regional and leading mode variability in the PI (panels $c$ and $g$ in Fig. 7, Table 4), but not in the LGM (panels $d$ and $h$ in Fig. 7).

Finally, changes in the seasonality of surface climate variability might cause an altered signal recorded by proxies (Krinner and Werner, 2003). Figure 9 shows how the magnitude of the seasonal cycle varies for two ice core locations in Greenland during the LGM compared to PI: the seasonal cycle of temperature is enhanced at the station NASA-U in the LGM simulations, whereas it is comparable at Summit; the seasonal cycle of precipitation is substantially modified at both locations. Neglecting this change in seasonality might cause a bias in LGM temperature estimates based on water isotopes, since the $\delta^{18} \mathrm{O}$ signal recorded at the LGM would have a different seasonal imprint than during the PI (Steig et al., 1994; Krinner and Werner, 2003).

Our study shows how assuming modern climate relationships for past climates can produce erroneous interpretations of paleoclimate records. Modelers must also be cautious when interpreting simulations of the LGM, given that the models are not able to depict a consistent spatial pattern of surface climate or SLP variability in this climate state. In a few areas where the models do agree, it is possible to infer that in both climates a substantial amount of regional variability of either temperature or precipitation can be reliably reproduced, for example in southern Norway (Table 4 and Figs. 7 and 8) or in Labrador (Fig. 10, Table 4).

\section{Conclusions}

In this paper, we analyze surface climate variability in the extratropical North Atlantic using LGM and PI simulations from four climate models. We describe how changes in atmospheric variability may affect signals recorded by proxies. The main findings are:

- The interannual variability of Northern Hemisphere sea level pressure (SLP) is significantly reduced at the LGM.

- The seasonal cycle of sea level pressure variability is decreased during the LGM. The reduction is more prominent and significant in the winter months, when the variability is highest in both the PI and LGM climates.

- An NAO-like pattern is the leading mode of SLP variability in each LGM simulation examined, though it represents less interannual variability and the centers of action are weaker.

- The ice sheets and greenhouse gases largely determine the mean circulation and the amplitude of the leading mode of variability, while the SST/sea ice help to determine the amount of SLP variability. Different atmospheric models respond differently to the same ice sheet and greenhouse gas forcings, so simulated differences in the pattern and amplitude of the leading mode of SLP variability (NAO-like) appear to be sensitive to different model's physics and/or parameterizations.

- The relationship between atmospheric variability and surface climate variability is different during the LGM. Therefore, caution is necessary when interpreting proxy records using the modern relationship as an analog.

\section{Appendix A}

In order to compare the PI simulations with modern observations, the same analyses have been performed using the ERA-40 reanalysis and are shown in Fig. A1.

Acknowledgements. This work is part of the ARCTREC project and funded by the Norwegian Research Council. We acknowledge the participants of the PMIP2 project, the international modeling groups for providing their data for analysis, and the Laboratoire des Sciences du Climat et de l'Environnement (LSCE) for collecting and archiving the model data. The PMIP2/MOTIF Data Archive is supported by CEA, CNRS, the EU project MOTIF (EVK2-CT-2002-00153) and the Programme National d'Etude de la Dynamique du Climat (PNEDC). More information is available on http://pmip2.lsce.ipsl.fr/. ERA40 reanalysis data are provided by the European Centre for Medium-Range Weather Forecasts, Reading, England, UK ( http://www.ecmwf.int/). NCEP Reanalysis data are provided by the NOAA/OAR/ESRL PSD, Boulder, 
a)

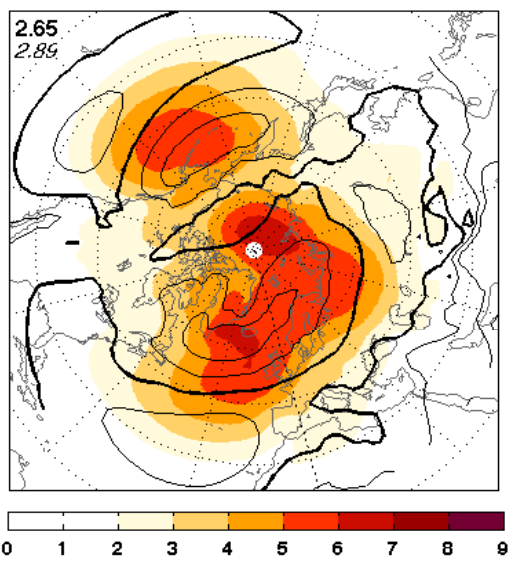

c)

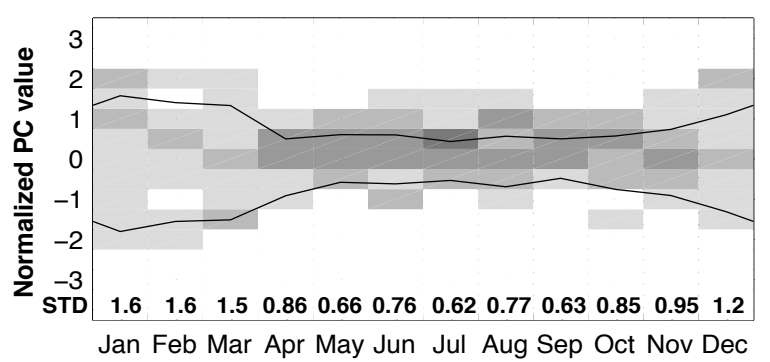

b)

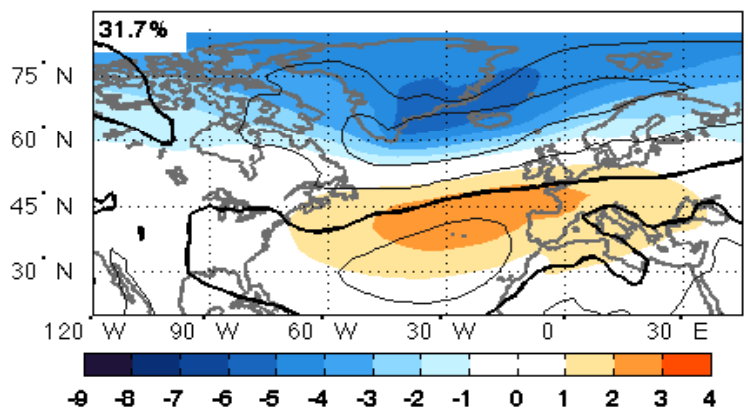

d)

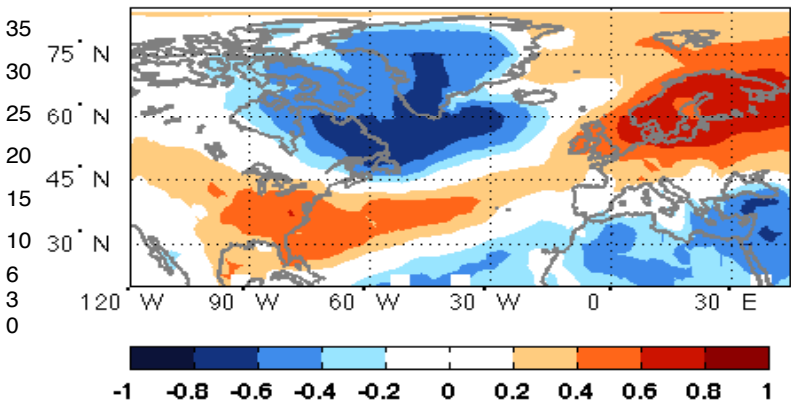

Fig. A1. ERA-40 reanalysis for the period 1957-2002; (a) The mean (contours) and standard deviation (colored shading: hPa) of monthly SLP averaged over all months; (b) Leading EOF of monthly SLP anomalies (colored shading: hPa/standard deviation of PC) and SLP climatology (contours) in the North Atlantic sector (all months). Number shows the amount of variance explained by the first mode as a percentage of the total variance $\left(\lambda_{1}\right)$; in both panels the contours have $4 \mathrm{hPa}$ interval from 1000 to $1040 \mathrm{hPa}$, bold contour denotes $1016 \mathrm{hPa}$; (c) Histogram of the leading principal component (PC1) of SLP as a function of month. For each month, the PC has been normalized by the standard deviation of the annually averaged PC1. The standard deviations of the PC in these normalized units are indicated along the $x$-axis for each month and are marked by the lines; (d) Correlations between North Atlantic winter surface air temperature and PC1.

Colorado, USA, from their Web site at http://www.cdc.noaa.gov/. This paper is Bjerknes Centre for Climate Research contribution number A 250.

Edited by: M. Crucifix

\section{References}

Allen, J. R. M., Brandt, U., Brauer, A., Hubberten, H. W., Huntley, B., Keller, J., Kraml, M., Mackensen, A., Mingram, J., Negendank, J. F. W., Nowaczyk, N. R., Oberhansli, H., Watts, W. A., Wulf, S., and Zolitschka, B.: Rapid environmental changes in southern Europe during the last glacial period, Nature, 400, 740743, 1999.

Appenzeller, C., Schwander, J., Sommer, S., and Stocker, T. F.: The North Atlantic Oscillation and its imprint on precipitation and ice accumulation in Greenland, Geophys. Res. Lett., 25, 1939 1942, 1998.
Bahr, A., Arz, H., Lamy, F., and Wefer, G.: Late glacial to Holocene paleoenvironmental evolution of the Black Sea, reconstructed with stable oxygen isotope records obtained on ostracod shells, Earth Planet. Sci. Lett., 241, 863-875, 2006.

Bakke, J., Lie, O., Nesje, A., Dahl, S., and Paasche, O.: Utilizing physical sediment variability in glacier-fed lakes for continuous glacier reconstructions during the Holocene, northern Folgefonna, western Norway, Holocene, 15, 161-176, 2005.

Braconnot, P., Otto-Bliesner, B., Harrison, S., Joussaume, S., Peterchmitt, J.-Y., Abe-Ouchi, A., Crucifix, M., Driesschaert, E., Fichefet, T., Hewitt, C. D., Kageyama, M., Kitoh, A., Laine, A., Loutre, M.-F., Marti, O., Merkel, U., Ramstein, G., Valdes, P., Weber, S. L., Yu, Y., and Zhao, Y.: Results of PMIP2 coupled simulations of the Mid-Holocene and Last Glacial Maximum Part 1: experiments and large-scale features, Clim. Past, 3, 261277, 2007.

Christoph, M., Ulbrich, U., Oberhuber, J. M., and Roeckner, E.: The role of ocean dynamics for low-frequency fluctuations of the NAO in a coupled ocean-atmosphere GCM, J. Climate, 13, 2536-2549, 2000. 
Collins, W. D., Rasch, P. J., Boville, B. A., Hack, J. J., McCaa, J. R., Williamson, D. L., Briegleb, B. P., Bitz, C. M., Lin, S. J., and Zhang, M. H.: The formulation and atmospheric simulation of the Community Atmosphere Model version 3 (CAM3), J. Climate, 19, 2144-2161, 2006.

Dansgaard, W., Johnsen, S. J., Clausen, H. B., Dahjensen, D., Gundestrup, N. S., Hammer, C. U., Hvidberg, C. S., Steffensen, J. P., Sveinbjorndottir, A. E., Jouzel, J., and Bond, G.: Evidence for General Instability of Past Climate from a 250-Kyr Ice-core Record, Nature, 364, 218-220, 1993.

Deser, C., Walsh, J. E., and Timlin, M. S.: Arctic sea ice variability in the context of recent atmospheric circulation trends, J. Climate, 13, 617-633, 2000.

Donohoe, A. and Battisti, D. S.: Causes of reduced North Atlantic Storm Activity in a CCSM3 simulation of the Last Glacial Maximum, personal communication, 2009.

Feldstein, S. B.: The recent trend and variance increase of the annular mode, J. Climate, 15, 88-94, 2002.

Gladstone, R., Ross, I., Valdes, P., Abe-Ouchi, A., Braconnot, P., Brewer, S., Kageyama, M., Kitoh, A., Legrande, A., Marti, O., Ohgaito, R., Otto-Bliesner, B., Peltier, W., and Vettoretti, G.: Mid-Holocene NAO: A PMIP2 model intercomparison, Geophys. Res. Lett., 32, L16707, doi:\{10.1029/2005GL023596\}, 2005.

Glueck, M. F. and Stockton, C. W.: Reconstruction of the North Atlantic Oscillation, 1429-1983, Int. J. Climatol., 21, 1453-1465, 2001

Hurrell, J. W.: Decadal Trends in the North Atlantic Oscillation - Regional Temperatures and precipitation, Science, 269, 676679, 1995.

Hutterli, M. A., Raible, C. C., and Stocker, T. F.: Reconstructing climate variability from Greenland ice sheet accumulation: An ERA40 study, Geophys. Res. Lett., 32, 2005.

Jouzel, J., Lourius, C., Johnsen, S., and Grootes, P.: Climate Instabilities - Greenland and Antarctic Records, Comptes Rendus De l' Academie Des Sciences Serie II, 319, 65-77, 1994.

Justino, F. and Peltier, W.: The glacial North Atlantic Oscillation, Geophys. Res. Lett., 32, L21803, doi:\{10.1029/2005GL023822\}, 2005.

Kistler, R., Kalny, E., and Collins, W.: The NCEP-NCAR 50-year reanalysis: monthly means CD-ROM and documentation, Bull. Am. Meteor. Soc., 82, 247-268, 2001.

Krinner, G. and Werner, M.: Impact of precipitation seasonality changes on isotopic signals in polar ice cores: a multi-model analysis, Earth Planet. Sci. Lett., 216, 525-538, 2003.

Kushnir, Y., Robinson, W. A., Blade, I., Hall, N. M. J., Peng, S., and Sutton, R.: Atmospheric GCM response to extratropical SST anomalies: Synthesis and evaluation, J. Climate, 15, 2233-2256, 2002.

Laîné, A., Kageyama, M., Salas-Mèlia, D., Voldoire, A., Riviére, G., Ramstein, G., Planton, S., Tyteca, S., and Petershmitt, J. Y.: Northern hemisphere storm tracks during the last glacial maximum in PMIP2 ocean-atmosphere models, J. Climate, 2008.

Li, C. and Battisti, D. S.: Reduced Atlantic storminess during Last Glacial Maximum: Evidence from a coupled climate model, J. Climate, 2008.
Miller, R. L., Schmidt, G. A., and Shindell, D. T.: Forced annular variations in the 20th century intergovernmental panel on climate change fourth assessment report models, J. Geophys. Res.Atmos., 111, D18101, doi:10.1029/2005JD006323, 2006.

Otto-Bliesner, B. L., Brady, E. C., Clauzet, G., Tomas, R., Levis, S., and Kothavala, Z.: Last Glacial Maximum and Holocene climate in CCSM3, J. Climate, 19, 2526-2544, 2006.

Peltier, W. and Solheim, L.: Dynamics of the ice-age Earth: Solid mechanics and fluid mechanics, J. Phys. IV, 12, 85-104, 2002.

Peltier, W. R.: Global glacial isostasy and the surface of the ice-age earth: The ice-5G (VM2) model and grace, Annu. Rev. Earth Pl. Sc., 32, 111-149, 2004.

Raible, C. C. Casty, C., Luterbacher, J., Pauling, A., Esper, J., Frank, D. C. Buntgen, U., Roesch, A. C., Tschuck, P., Wild, M., Vidale, P. L., Schar, C., and Wanner, H.: Climate variability-observations, reconstructions, and model simulations for the Atlantic-European and Alpine region from 1500 2100 AD, Clim. Change, 79, 9-29, 2006.

Seierstad, I. A. and Bader, J.: Impact of a projected future Arctic Sea Ice reduction on extratropical storminess and the NAO, Clim. Dynam., available at: http://www.springerlink.com/content/f843225242338024/ $? \mathrm{p}=2 \mathrm{e} 6 \mathrm{e} 7 \mathrm{fd} 67641427 \mathrm{~d} 82 \mathrm{db} 0 \mathrm{a} 37 \mathrm{aaae} 483 \mathrm{~d} \& \mathrm{pi}=4,2008$.

Shackleton, N.: Paleoclimate - Climate change across the hemispheres, Science, 291, 58-59, 2001.

Shindell, D. T., Miller, R. L., Schmidt, G. A., and Pandolfo, L.: Simulation of recent northern winter climate trends by greenhouse-gas forcing, Nature, 399, 452-455, 1999.

Steig, E. J., Grootes, P. M., and Stuiver, M.: Seasonal Precipitation Timing and Ice Core Rrecords, Science, 266, 1885-1886, 1994.

Uppala, S. M., Kallberg, P. W., Simmons, A. J., Andrae, U., Bechtold, V. D., Fiorino, M., Gibson, J. K., Haseler, J., Hernandez, A., Kelly, G. A., Li, X., Onogi, K., Saarinen, S., Sokka, N., Allan, R. P., Andersson, E., Arpe, K., Balmaseda, M. A., Beljaars, A. C. M., Van De Berg, L., Bidlot, J., Bormann, N., Caires, S., Chevallier, F., Dethof, A., Dragosavac, M., Fisher, M., Fuentes, M., Hagemann, S., Holm, E., Hoskins, B. J., Isaksen, L., Janssen, P. A. E. M., Jenne, R., McNally, A. P., Mahfouf, J. F., Morcrette, J. J., Rayner, N. A., Saunders, R. W., Simon, P., Sterl, A., Trenberth, K. E., Untch, A., Vasiljevic, D., Viterbo, P., and Woollen, J.: The ERA-40 re-analysis, Q. J. Roy. Meteor. Soc., 131, 29613012, 2005.

Voigt, R., Grueger, E., Baier, J., and Meischner, D.: Seasonal variability of Holocene climate: a palaeolimnological study on varved sediments in Lake Jues (Harz Mountains, Germany), J. Paleolimnol., 40, 1021-1052, 2008. 